\title{
Loterías, justicia e imparcialidad: el caso de la asignación de vacunas
}

Jesús Ernesto Macías Gil

Universidad Nacional Autónoma de México Instituto de investigaciones filosófica/ Facultad de Filosofía y letras jemaciasgil@comunidad.unam.mx

\section{Introducción}

Mi objetivo en este texto es argumentar sobre la idea de que una lotería justa es un mecanismo de asignación más justo en el caso de la asignación de vacunas en casos de emergencia. Al decir que es más justo, lo hago en contraposición a la propuesta de lotería cargada de Martin Peterson (2008). Una intención secundaria es caracterizar la propuesta de Peterson como una propuesta que es sólo en apariencia un mecanismo de asignación por aleatoriedad, por lo que termina siendo una forma de asignación injusta si se parte de determinado principio de justicia.

Para lograr esto, en un primer momento, expondré el caso de la asignación de vacunas en casos de emergencias, esto para poder dibujar la propuesta de Peterson dentro del contexto en el que nace y el problema que trata de resolver. Posteriormente, buscaré caracterizar la propuesta de Peterson como una lotería cargada; para esto, describiré el tipo de 
mecanismo que son las loterías y propondré algunos criterios añadidos a los ya dados para considerar que está justificado tanto el uso de loterías como el de mecanismo de asignación.

Mi énfasis estará en delinear lo que, siguiendo a Stone (2011), llamaré la lotería justa. La idea es que una lotería justa cumple con los criterios para ser invocada, además de que es una forma de romper la indeterminación generada por la incapacidad de deliberar, para concluir en que sólo una lotería justa es una lotería en sentido estricto, según la descripción de un mecanismo por aleatoriedad.

En el tercer paso hablaré de cómo el uso de loterías, en el caso de la asignación de vacunas, se justifica sólo si hay aspectos de justicia involucrados. Trataré de encontrar la relación entre algunos principios de justicia generales con un principio determinado de imparcialidad. Concluyendo que la lotería justa puede respetar dicho principio mientras que la lotería cargada no. Finalmente analizaré algunas críticas a la propuesta y sus elementos.

\section{Un caso de emergencia}

En junio de 2009, la Organización Mundial de la Salud declaró que el nivel de alerta por la infección de influenza tipo A, subtipo H1N1, había llegado a ser una "pandemia», lo que significaba que la infección se había extendido a nivel mundial y que las personas afectadas no mostraban una reacción inmune favorable (OMS, 2016). A raíz de este suceso se implementaron medidas sanitarias para contener el avance de la infección a nivel geográfico. Una de las medidas obvias que se toma en casos similares es la distribución de vacunas - en caso de que las haya- contra la infección. 
Una pregunta interesante nace entonces, ¿cómo es que se asignan ${ }^{1}$ estas vacunas? Los criterios para la asignación pueden parecer obvios prima facie, sin embargo, al contrastar lo que las intuiciones comunes nos dicen con cómo de hecho se realizan las asignaciones, podríamos encontrar una asimetría que nos haría pensar en que los principios por los cuales se realiza la asignación de vacunas no son aceptables. Para ilustrar esto lo mejor será recurrir a algunos ejemplos.

El caso de los protocolos de asignación

Hablemos acerca de los protocolos reales de asignación de vacunas en caso de emergencia. La OMS estipula que cada nación debe articular protocolos propios para la asignación de recursos de salud en casos de emergencia como las pandemias; sin embargo, exhorta a las autoridades de salud a que sus protocolos tomen en cuenta subgrupos de importancia tales como personal y auxiliares médicos, personal de auxilio y emergencias, además de líderes y autoridades de primer y segundo orden (Peterson, 2008). Algunos protocolos de asignación que cumplen con dicha observación son los siguientes:

1 Utilizaré el término «asignación» y no «distribución», y entenderé los términos como no intercambiables, porque considero que hay una diferencia entre «asignar» un bien y «distribuir» un bien. Planteo la diferencia de la siguiente forma: asignar un bien es simplemente señalar quién o quiénes lo recibirán, mientras que distribuir implica una acción de otorgar «en mano propia» dicho bien. Dicho de otra forma, la asignación es un paso previo para la distribución y la asignación es hecha directamente por un solo agente. Para una descripción más informada sobre la distinción se puede consultar a Stone (2007). Por supuesto que esta distinción queda abierta a corrección. 
El plan canadiense

Grupo 1: Trabajadores de salud, responsables de la salud pública y administradores de recursos de salud

Grupo 2: Responsables del sector social en caso de pandemias y administradores del sector social

Grupo 3: Personas con alto riesgo de mortalidad por una infección

Grupo 4: Adultos saludables

Grupo 5: Niño de 24 meses a 18 años de edad

El plan canadiense contempla como prioridad de asignación a trabajadores y funcionarios del sector salud.

El plan británico

Grupo 1: Trabajadores de salud en contacto con los pacientes (incluyendo personal de ambulancias) y personal en hogares de cuidado para ancianos.

Grupo 2: Prestadores de servicios esenciales, por ejemplo, bomberos, policia, seguridad, comunicaciones, servicios de agua, luz y gas funerarios, ejercito

Grupo 3: Aquellos con alto riesgo para la salud (por ejemplo, enfermedades respiratorias crónicas o del corazón, falla renal, diabetes mellitus o inmunodeficiencia debido a enfermedad o tratamiento, mujeres en el último trimestre del embarazo

Grupo 4: Todos los mayores de 65 años

Grupo 5: Industrias seleccionadas

Grupo 6: Grupos seleccionados según edad, siguiendo el consejo de la OMS (e.g. niños)

Grupo 7: Ofrecerla a todos 
El plan británico contempla como prioridad al personal de salud en contacto con pacientes de alto riesgo así como a empleados que proveen servicios básicos como la policía, personal de comunicaciones, bomberos, fuerzas armadas, etc.

Tabla 1. Propiedades de asignación de vacunas según servicio proporcionado.

\begin{tabular}{lll}
\hline $\begin{array}{l}\text { Nivel } \\
\text { de prioridad }\end{array}$ & Servicios esenciales & $\begin{array}{l}\text { Total } \\
\text { de personal }\end{array}$ \\
& & $\begin{array}{l}\text { Quienes deberían recibir } \\
\text { medicamentos anti- } \\
\text { virales si están enfermos } \\
\text { (o vacuna) }\end{array}$ \\
\hline
\end{tabular}

\begin{tabular}{|c|c|c|c|}
\hline $\begin{array}{l}\text { Prioridad } \\
\text { alta }\end{array}$ & $\begin{array}{l}\text { Doctores } \\
\text { Enfermeras + auxiliares de } \\
\text { enfermería } \\
\text { Personal de laboratorio } \\
\text { médico }\end{array}$ & 50 & 50 \\
\hline $\begin{array}{l}\text { Segunda } \\
\text { prioridad }\end{array}$ & $\begin{array}{l}\text { Para tratar pacientes de alto } \\
\text { riesgo }\end{array}$ & 50 & \\
\hline $\begin{array}{l}\text { Tercera } \\
\text { prioridad }\end{array}$ & $\begin{array}{l}\text { Presidente, gabinete, secre- } \\
\text { tario en jefe } \\
\text { Policía } \\
\text { Conductores de ambulancia } \\
\text { Aero Nauru } \\
\text { Aeropuerto } \\
\text { Aduana e inmigración } \\
\text { Brigada de bomberos } \\
\text { Servicios portuarios } \\
\text { Cuarentena médica } \\
\text { Comunicaciones } \\
\text { Servicios (agua, electrici- } \\
\text { dad, combustibles) }\end{array}$ & $\begin{array}{r}15 \\
26 \\
100 \\
2 \\
38\end{array}$ & $\begin{array}{r}7 \\
50 \\
3 \\
37 \\
3 \\
2 \\
12 \\
30 \\
2 \\
4 \\
8\end{array}$ \\
\hline Total & & & 266 \\
\hline
\end{tabular}




\section{El plan nauriano}

El plan de Nauru ${ }^{2}$ contempla como prioridad tanto al personal médico como funcionarios de primer y segundo orden, incluidos el presidente y su gabinete, así como cabezas de instituciones de gobierno.

En su artículo de 2008, Martin Peterson se pregunta si este tipo de protocolos y los principios bajo los que se constituyen pueden ser considerados como aceptables moralmente. La intuición clave de Peterson es que, al parecer, todos estos protocolos se basan en un principio utilitarista que termina por ser moralmente inaceptable (2008). La propuesta alternativa de Peterson a este tipo de protocolos es proponer el uso de loterías para la asignación de vacunas como una propuesta con consecuencias morales mucho más aceptables.

Mi interés no se centra en el problema de las posibles implicaciones éticas de la asignación por loterías, sino más bien en lo que implica para ciertos principios de justicia el utilizar un método no discrecional como el de la lotería. Es por esto que no me centraré en la discusión relacionada con lo que Peterson considera el aspecto moral de las loterías; sin embargo, me interesa poner atención en una afirmación que hace y que, me parece, introduce la cuestión del uso de loterías en terrenos relacionados con las teorías de la justicia. En su artículo, después de exponer el problema moral obvio en la asignación por protocolos (a quién debemos salvar y por qué), Peterson dice lo siguiente:

2 Nauru es una pequeña isla perteneciente a Micronesia. Su extensión territorial es de aproximadamente $21 \mathrm{~km}^{2}$. 
Mi opinión no implica que todos deberían tener el mismo derecho a la igualdad de posibilidades de tener una dosis de la vacuna. Es más probable que algunas personas, como médicos y enfermeras, puedan estar más expuestas al virus y deberían por lo tanto recibir un mayor número de boletos de lotería que, por decir algo, los profesores de universidades (2008: 324).

Ahora bien, ¿por qué esta afirmación es importante para lo que intento analizar? La respuesta tiene que ver más con hacer honor a ciertos principios de justicia que al aprecio que le tengo o tuve a mis profesores de la universidad. La idea es si esta forma de lotería propuesta por Peterson no termina siendo una forma injusta de asignación. Siguiendo a Hirose en su réplica a Peterson, me parece que este tipo de lotería en la que Peterson pensaba es una forma de «lotería cargada» (weighted lottery) (Hirose, 2010), lo que implica por exclusión que no se trata de una «lotería justa». Para continuar con mi argumentación de por qué considero la propuesta de Peterson una forma injusta de asignación en el caso de las vacunas, es necesario que explique la diferencia entre una lotería justa y otros tipos de loterías, y para ello es necesario que explique en qué tipo de mecanismo de asignación se piensa cuando se habla de loterías.

\section{Loterías y lotería justa}

La palabra lotería puede dirigirnos automáticamente a otra serie de conceptos relacionados, por ejemplo, suerte, azar, probabilidad, indeterminación y hasta fortuna. Todo esto se debe a que dichos conceptos conforman, de una $u$ otra manera, parte de lo que es una lotería. De forma preliminar, po- 
dríamos usar una definición como: «una lotería es un proceso capaz de generar un conjunto de resultados, en el cual el resultado particular esperado cada vez que el proceso ocurre es impredecible dada la información disponible ${ }^{3} \gg$ (Stone, 2011: 20).

Esta definición nos dice algo acerca de por qué al hablar de loterías podemos relacionarlas con conceptos como el de indeterminación y azar, pero también nos dice que hay conceptos con los que, de forma inicial, una lotería no está relacionada, por ejemplo, el concepto de justicia. En lo que sigue, trataré de explicar lo que se entiende por una lotería para asignaciones de bienes, así como la diferencia entre una lotería cargada y una lotería justa.

¿Cuándo se usan loterías? (si es que se usan o se han usado)

Pensemos en el caso de la asignación de vacunas en casos de emergencia: ¿realmente es una situación en la que haya que utilizar loterías? Antes de caer en una petición de principio, establecer que el caso analizado es del tipo de casos en los que se puede invocar una lotería no demuestra lo que me he propuesto al inicio del texto (pensar en el uso de loterías justas como un mecanismo de asignación más justo), sino que propone un primer paso a desarrollar la diferencia entre una lotería cargada y una lotería justa. Regresaré a esto más adelante.

Existen criterios dados para pensar en que el uso de una lotería para la asignación es adecuado, y podemos pensar en algunos otros. No pienso que pueda haber una serie de criterios generales que establezcan cuándo en todo caso que cumpla ciertas condiciones, se pueda utilizar una lotería.

3 Las cursivas son del texto original. 
«Lanzar una moneda en general es una cosa, lanzar una moneda en particular en un particular tiempo y momento es otra» (Stone, 2011: 20). Uso esta distinción para enfatizar que al pensar en criterios para el uso de loterías, se debe pensar en casos específicos y no en tipos generales.

Volviendo a los criterios para determinar cuándo el uso de loterías es una opción, podemos comenzar pensando en algunos de los dados por Jon Elster. Primero, se puede pensar en el uso de loterías cuando existen diversas opciones igual y máximamente buenas (1989). Pensemos, por ejemplo, en el caso de tener que decidir entre dos frutas igualmente maduras y del mismo peso en el mercado, o cualquier otra decisión en la que el resultado (mas no el proceso de selección) tenga la misma consecuencia deseable. Segundo, cuando la opción que ocupa el puesto más alto en la deliberación es inconmensurable ${ }^{4}$, pensemos por ejemplo en casos en los que somos incapaces de ponderar o comparar los resultados de diferentes acciones que podemos elegir (Elster, 1989). Finalmente, los casos en los que las opciones al puesto más alto son igualmente buenas hasta donde sabemos, y no vale la pena molestarse en buscar más. Por supuesto, un análisis más detallado podría llevarnos a darnos cuenta de que una opción es superior a otra; sin embargo, la ganancia podría ser mínima

4 Puede haber muchas causas de esta falta de capacidad para medir las preferencias en la deliberación. Pensando en aspectos conductuales sobre las preferencias de los agentes, se puede pensar en casos en los que en un juego no cooperativo con estrategias mixtas un agente decida no tomar en cuenta una preferencia, esperando a que otro agente tome la decisión que deje una sola opción por la cual decantarse. Por otro lado, puede haber ausencia total de buenas razones por parte del agente para encontrar una solución al dilema de su deliberación. Finalmente, lo que pone el dedo sobre la cuestión de una opción inconmensurable es cuando el agente tiene un orden incompleto de preferencias que lo imposibilitan a ponderar y comparar sus opciones, dejándolo sin la posibilidad de determinar qué acción sería la óptima (Elster, 1989). Un análisis más detallado del tema se encuentra en Elster (1989), y el trasfondo necesario para comprender la jerga involucrada de teoría de juegos y elección racional se puede obtener de Binmore (2011). 
en comparación con el costo de adquirir esa información adicional (Elster, 1989). ${ }^{5}$

Estos criterios comienzan a dar un poco de luz sobre las situaciones en las que parece una opción razonable invocar una lotería; sin embargo, estos criterios se enfocan en casos en los que la lotería soluciona un curso de acción y no una asignación, en todo caso, este tipo de loterías serían útiles para poder elegir usar una lotería o no. Viéndolo así, parece ser un juego propio de comité universitario, en el que se vota para saber si se debe votar. Sin embargo, es ilustrativo un punto que está presente en los tres criterios: tomar en cuenta las loterías cuando hay dos o más opciones igualmente buenas.

Pensemos ahora en aplicar esto en un contexto en el que las loterías ya no se usan para deliberar acerca de lo que uno podría o no hacer, sino acerca de a quién o a quiénes uno podría asignar un bien. Pensemos pues en el contexto de las «loterías sociales» o, más apropiado, el uso de loterías para asignación de bienes y cargas. Existen pocos casos, aunque sustanciosos, en los que se han utilizado loterías para la asignación de bienes y cargas. Algunos ejemplos son el sorteo para determinar quiénes realizarán el servicio militar en México, los concursos por plazas laborales, los asensos para empleados con la misma antigüedad, la asignación de órganos para trasplantes entre pacientes con las mismas demandas, etcétera.

Lo interesante en estos casos es la analogía que se puede hacer con los criterios de las loterías como una forma de decidir qué hacer. De esta forma podríamos decir que el aná-

5 Esto pensando en casos en los que el tiempo «apremia» o uno no puede «darse el lujo» de obtener más información. En estos casos, parece que sería irracional o «inadecuado» detenerse a pensar o a pedir más información. Pienso que el caso de asignación de bienes médicos en caso de emergencia podría ser uno de esos casos. 
logo a «dos opciones igualmente buenas» podría ser «dos receptores igualmente necesitados». Habría que aclarar que el criterio de necesidad no puede, por sí solo, ser un criterio suficiente para invocar una lotería, sin embargo, la necesidad aunada a cuestiones como el tipo de demanda realizada para satisfacerla ofrece un criterio más sólido y robusto. Basado en esto y en las precisiones hechas por Stone y Elster respecto a cuándo es aceptable el uso de loterías para asignación de bienes (Elster, 1989; Stone, 2011), propongo aceptar los siguientes criterios:

1. Que las demandas de los receptores tengan una fuerza tal que no puedan ser superadas por las de ningún otro receptor, obviando el hecho de que debe haber más de un receptor cuyas demandas cumplan con esta característica.

2. Que no exista un factor extraordinario de desempate, o lo que es lo mismo, que no exista la posibilidad de que un factor ajeno a los mismos receptores hiciera que una de sus demandas tuviera más fuerza.

3. Que el bien a asignar sea escaso e indivisible, además de poder ser intercambiable, es decir, que no exista una razón de peso para preferir una unidad específica sobre otra.

4. Que exista un factor de presión que imposibilite extender por demasiado tiempo la deliberación sobre a qué receptor debería asignársele el bien.

No pretendo que estos criterios sean de alguna forma necesarios y suficientes, de hecho, debo pedir que estos sean contemplados sólo como justificaciones para el uso de loterías en el caso de la asignación de vacunas en casos de emergencia. 
Esto puede ser visto como una trampa argumentativa, pero más que eso busco hacerle justicia a la intuición de que los mecanismos de asignación obedecen a principios de justicia determinados, y estos principios son variables según el caso y sus particularidades ${ }^{6}$. Ahora bien, la cuestión importante es determinar cómo la propuesta de la lotería, tal y como la plantea Peterson, termina por ser un caso de lotería cargada $\mathrm{y}$, por lo tanto, injusta. Para esto pasaré de haber planteado cuándo es aceptable usar la lotería como mecanismo de asignación a mostrar la diferencia entre una lotería cargada y una lotería justa.

Lotería cargada vs. Lotería justa

Hablemos un poco de indeterminación y discrecionalidad como algo necesario para pasar al concepto de lotería justa. Un mecanismo de asignación discrecional es aquel en el que los agentes que realizan la asignación toman «a discreción», es decir, según ellos decidan de acuerdo con sus preferencias, las razones por las cuales un bien debe ser asignado a determinado receptor. En contraposición, un mecanismo «mecánico» es aquel en el que, dada cierta indeterminación, quedan reducidas al mínimo -si no es que eliminadas del todo- las preferencias de los agentes que asignan.

Antes de continuar con el argumento principal, una precisión más. La indeterminación debe ser entendida en este contexto como la imposibilidad total de decidir entre una opción $\mathrm{u}$ otra por falta de información relevante. Elster consi-

6 Esta intuición no es sólo mía, sino que más bien la comparto de autores como Elster que plantean el caso de los principios de asignación como cambiantes según las exigencias de justicia de casos y contextos determinados (Elster, 1992; Elster, 2000). 
deraba que el hecho de que existiera indeterminación en una elección era razón suficiente para invocar el uso de loterías, sin embargo, esto no significaba que de hecho hubiera buenas razones para usarlas, ya que de hecho algunas decisiones son lo suficientemente banales como para que la indeterminación no las afectara, lo que hace la diferencia y convierte las loterías en una opción real es el que la justicia se vea involucrada (1989: 107-109).

Ahora me tomo la libertad de citar algunos pasajes acerca de cómo una lotería bien realizada rompe con la indeterminación:

Una lotería, a mi parecer, es un proceso capaz de generar varios posibles resultados. El resultado específico que será generado por la lotería en cada ocasión dada que se utilice es desconocido (Stone, 2007: 279-280).

Un agente que emplea una lotería en este sentido está concediendo un bien a quien lo demanda si resulta seleccionado cuando la lotería es usada. Si quienes demandan un bien tienen demandas igualmente fuertes, entonces un proceso de toma de decisiones que involucra loterías asegura que uno de esos demandantes será seleccionado para recibir el bien, pero la identidad exacta de ese demandante es desconocida hasta que la lotería es empleada (Stone, 2007: 280).

Hasta ahora estas afirmaciones apuntan hacia que es necesario que las loterías cumplan con cierta aleatoriedad. Esto aún no asegura que toda lotería sea usada bajo indeterminación, ya que desconocer la identidad específica del posible recep- 
tor no asegura que, de hecho, no se tenga información que privilegie un resultado sobre otro:

Si la garantía para predecir que un resultado va a darse es exactamente la misma que la garantía para creer que cualquier otro resultado va a ocurrir, entonces la lotería es una lotería justa. Si esto no es el caso, si hay más garantías para creer que algún resultado va a ocurrir en lugar de otros, entonces la lotería es una lotería cargada (esto es, cargada hacia cierto resultado). Si uno equipara la garantía para creer que un resultado va a ocurrir con la probabilidad de que el resultado va a ocurrir, entonces uno puede adelantarse a definir una lotería justa como una lotería en la cual los resultados son todos equiparables, y una lotería cargada como una lotería en la cual diferentes resultados tienen diferentes probabilidades $^{7}$ (Stone, 2007: 280).

Finalmente podemos decir que las condiciones de indeterminación para el uso de una lotería no se limitan a no disponer de información relevante para tomar una decisión directa, sino también a una falta de información acerca de quiénes serán los receptores específicos del bien y una falta de información sobre las posibilidades de los receptores de recibir el bien. Finalmente se puede hablar de una regla de la lotería justa como la plantea Stone:

Bajo condiciones de indeterminación, si un agente debe asignar un bien escaso indivisible y homogéneo entre un grupo de individuos con demandas homogé-

$7 \quad$ Las cursivas son del texto original. 
neas, entonces ese agente debe recurrir al uso de una lotería justa (2011: 53).

Ahora viene lo interesante. Regresando al caso de la asignación de vacunas en casos de emergencia, la propuesta de Peterson resulta no ser una propuesta justa al tratarse de una lotería cargada, ya que la propuesta pide que se asigne un mayor número de boletos para la lotería a determinado grupo, lo que altera las posibilidades de que reciban la vacuna cargándose a su favor. Si bien existe aún la posibilidad de que no resulten sorteados, el hecho es que el agente que hace la asignación termina por favorecer a un determinado grupo al hacer que los posibles resultados de la lotería tengan distintas probabilidades de darse.

Esto podría pensarse como una consecuencia inevitable $y$ un defecto del proceso, pero el hecho es que el conocimiento del agente que asigna las oportunidades para el sorteo convierte al tipo de asignación propuesto por Peterson en una especie de mecanismo discrecional disfrazado. Lo mismo que Elster afirmaba sobre las explicaciones funcionales en su crítica a Calabresi y Bobbit (1992) puede decirse de esta propuesta que tiene la tendencia a disimular u ocultar la necesidad de tomar «decisiones trágicas» con la ilusión de que no se está realizando una asignación discrecional, sin embargo dicha ilusión puede no sostenerse por mucho tiempo.

Hasta ahora sólo he dicho que, según lo que he explicado, la propuesta de Peterson no pasa la prueba de la lotería justa de acuerdo con los criterios que tomé de Elster y Stone. Pero cabe el preguntarse si de hecho una lotería justa es un método más justo de asignación que el propuesto por Peterson tomando en cuenta criterios más robustos como principios de justicia determinados. Lo que haré a continuación 
será tratar de responder a esto al contrastar la propuesta de lotería cargada de Peterson y la de la lotería justa con determinados principios de justicia.

\section{Justicia e imparcialidad}

En el apartado anterior mencioné cómo para Elster las loterías cobraban importancia al involucrarse con la idea de justicia. También obvié la relación entre cuestiones de justicia y las loterías proponiendo solo la idea de lotería justa, sin embargo, es prudente preguntarse si de hecho existe una relación importante entre un mecanismo de asignación del tipo del que son las loterías con cuestiones de justicia. Lo que pretendo hacer ahora es demostrar esa relación.

En uno de sus textos más conocidos, John Broome relaciona la idea del uso de loterías con una asignación justa para satisfacer las demandas de los receptores. Básicamente, Broome propone que una lotería como tal termina favoreciendo a quienes no tienen las demandas más fuertes de un bien, esto es, a quienes no lo requieren con mayor necesidad. Por esta razón Broome cree que lo más justo sería utilizar una lotería en la que la mayor probabilidad de obtener un bien esté cargada hacia los receptores que tienen una demanda más fuerte (1990).

Este ejemplo obviamente deja ver una inclinación a la idea de una lotería cargada; sin embargo, lo importante aquí es por qué Broome considera que esto debe ser así. La razón es que para Broome un principio de justicia que debe ser respetado es favorecer a aquellos que tienen una demanda con una mayor fuerza. Dejando fuera el hecho de que esto supondría, según la regla de la lotería justa, que una lotería en principio no debería ser invocada, y que resulta sólo otro 
caso de una decisión trágica disfrazada, el punto es que lo que vincula el uso de una lotería con la idea de justicia es el principio de justicia bajo el cual se justifica su uso y por el cual se pretende que sea una asignación más justa.

Si debemos pensar en principios de justicia, considero que lo más ilustrativo sería comenzar por retomar a John Rawls, porque me parece que no se puede hablar de principios de justicia sin hablar por lo menos de forma sucinta de John Rawls ${ }^{8}$. Articularé pues los dos principios más generales de justicia de la forma más fiel a como lo hace Rawls, o mejor aún, los citaré:

[...] El primero exige igualdad en la repartición de derechos y deberes básicos, mientras que el segundo mantiene que las desigualdades sociales y económicas, por ejemplo las desigualdades de riqueza y autoridad, sólo son justas si producen beneficios compensadores para todos y, en particular, para los miembros menos aventajados de la sociedad (2006: 27).

Ambos principios de justicia podrían ser homologados para el caso de la asignación de bienes, y me parece que exigirían de alguna forma que una asignación justa cumpliera con demandas de justicia tales que, por ejemplo, en el caso de una asignación de vacunas en caso de emergencias se respetara que 1) la asignación de vacunas se realizara de forma imparcial entre los posibles receptores y 2) que dicha imparcialidad sólo podría ser pasada por alto si el beneficio fuera general, o en el

8 Antes sería bueno recordar que incluso los críticos más duros de Rawls han coincidido en que su teoría de la justicia es el punto de partida indispensable. Parafraseando a John Austin en su defensa de las excusas, puede que las teorías de Rawls no tengan la última palabra, pero indudablemente tienen la primera. 
mejor de los casos, para favorecer a los más afectados por un brote o pandemia.

Ahora la pregunta por el premio frívolo ridículamente presentado es, ¿cumple la asignación por loterías con estos principios? Dado el orden lexicográfico de los principios de Rawls lo más conveniente sería comenzar por la idea de la imparcialidad.

Imparcialidad y loterías

Hace un momento utilicé el término «homologados» para referirme a la posibilidad de utilizar los principios de justicia generales de Rawls en el área específica de las asignaciones justas, esto fue intencional y se debió a que me parece que el marco normativo, tanto de los principios de Rawls como el de principios más específicos, puede ser el mismo.

Aun así, creo que no es del todo lícito tomar como tal el primer principio y hablar de un principio de imparcialidad al llevarlo al terreno de las asignaciones de bienes. Antes bien, creo que se debería formular un principio propio de imparcialidad para las asignaciones, para mi suerte; ya existe uno formulado por Peter Stone:

El principio de imparcialidad en consecuencia demanda que cuando un bien es asignado, un agente debe generar distribuciones que satisfagan condiciones de eficiencia, prioridad y equidad en la medida de lo posible. Dicho requisito es importante, porque la indeterminación hace imposible para cualquier tipo de distribución cumplir con esas tres condiciones al mismo tiempo (2011: 82). 
Lo importante al momento de aceptar dicho principio es entender cómo esto lleva necesariamente a que la única forma de asignación (y posteriormente distribución) que le haría honor es la lotería justa. Básicamente podemos pensar esto aplicándolo al caso que nos interesa. Dadas las condiciones que se requieren para poder realizar una asignación no aleatoria, tales como tener buenas razones para asignar de forma discrecional un bien, la lotería justa promete, en primer lugar, satisfacer las tres condiciones del principio de imparcialidad y, en segundo lugar, respetar la forma más general del principio entendiéndola como una igualdad de condiciones para la asignación de un bien.

En un caso de emergencia, asignar vacunas teniendo buenas razones para elegir algunos receptores sobre otros implicaría tener que buscar buenas razones para hacer dicha asignación, lo que consumiría tiempo que tal vez no se tenga, lo cual violaría la condición de eficiencia del principio y es, además, un criterio para tomar en cuenta el uso de la lotería. Por otro lado, una asignación discrecional no podría solucionar el problema que le pone la indeterminación, a menos que se tuviera más información relevante, lo cual puede llevar más tiempo, que puede no tenerse de sobra, y el círculo comienza de nuevo.

Ahora toca el turno de la propuesta de lotería cargada de Peterson y Broome. Siendo sincero, darle una oportunidad es sólo con el fin de demostrar que de hecho no puede siquiera pensar en hacerle honor al principio de imparcialidad, esto porque sólo un mecanismo que sea aleatorio podría hacerlo. La lotería cargada, como la he dibujado anteriormente, es sólo aleatoria en apariencia, ya que en principio es susceptible de los mismos problemas que una asignación discrecional. Pensemos cómo serían asignadas las oportunidades 
para participar en la lotería, al tener algunos más boletos para el sorteo que otros. Las preguntas obvias serían, ¿qué buenas razones tenemos para asignar los boletos de esa manera? y ¿tenemos de hecho buenas razones? Creo que no es necesario repetir a dónde nos lleva esto.

Finalmente, una lotería justa tiene mayores méritos para hacerle honor al principio de imparcialidad, porque, de entrada, como ya era planteado por Elster, una lotería es un mecanismo que se usa cuando la razón es insuficiente y es superada por la indeterminación, cuando no hay interés por las razones, cuando la indeterminación hace imposible razonar, y cuando la inconmensurabilidad nos deja sin poder deliberar (Elster, 1989). Así pues, sólo una lotería en sentido estricto podría cumplir con el principio de imparcialidad, y como ya he tratado de mostrar, la propuesta de Peterson no cumple con ser una lotería como tal. Sólo una lotería que cumpla con la regla de la lotería justa puede ser considerada como el mecanismo de asignación necesario que, en el caso de las vacunas en emergencias de salud, respetaría el principio de imparcialidad.

Lotería justa pero no lotería perfecta: a manera de conclusión

Hasta ahora me he concentrado en proponer la lotería justa como una propuesta que promete ser más justa a partir de ciertos principios de justicia, en contraposición a la propuesta de lotería de Peterson, y para el caso específico de la asignación de vacunas en casos de emergencia.

Ahora hablaré de las críticas que hasta el momento se me han ocurrido para la propuesta que traté de dibujar. En primer lugar, creo que una crítica obvia tiene que ver con 
el segundo principio de justicia de Rawls, que parece haber sido pasado por alto. De entrada, no se puede asegurar que una lotería cumpla con el favorecimiento de los menos favorecidos. Ni la lotería cargada de Peterson, que tendría el mismo problema del inicio tratando de determinar quiénes son los menos favorecidos, ni la lotería justa que he tratado de defender aquí, que en primer lugar anularía el estatus de un receptor menos favorecido al eliminar todo posible conocimiento específico de los receptores.

De ahí se desprende una objeción más. Parece ser que de entrada un mecanismo de asignación justo debería, por lo menos, tomar en cuenta de forma preliminar las demandas de los posibles receptores, esto con la finalidad de identificar a los menos favorecidos. No digo que las demandas sean el criterio último para determinar esto, ya que podemos pensar en demandas de personas favorecidas y en personas nada favorecidas, que por cualquier situación no hagan las demandas para satisfacer sus necesidades. Sin embargo, es un buen punto de partida o desempate en todo caso.

Otro problema tiene que ver con que aún no estoy convencido del todo de que la asignación de vacunas en casos de emergencia sea un caso en el que, de hecho, se deba invocar una lotería. Parece ser que el único criterio que se cumple de los que mencioné es el de la urgencia, ya que es difícil pensar en que haya receptores que demanden recibir un bien que quizá incluso no saben que necesitan, aunque he dicho que esto no significa que se deba descartar dárselos. La lotería cargada de Peterson y Broome cumple con esta intuición poderosa; sin embargo, ¿no es claro que si de hecho la razón para asignar un bien, en este caso vacunas, es la fuerza de las demandas, se tienen buenas razones para asignar el bien de forma directa? 
Finalmente, relacionado con esto está el hecho de que no es claro tampoco por qué un mecanismo como la lotería sería un mecanismo de asignación que de hecho debiera ser tomado en cuenta en el caso de las vacunas en caso de emergencias. Y uno podría preguntarse entonces por qué tanto problema para proponerlo como un mecanismo de asignación más justo, y el reclamo sería válido de cierta manera, pero no hay que olvidar que mi intención fue proponer la lotería justa como un mecanismo más justo en comparación con la lotería de Peterson, además de mostrar que esta última se trata sólo de un mecanismo discrecional disimulado bajo la capa de un mecanismo por aleatoriedad.

Sin embargo, retomando de nuevo a Elster (1992), los mecanismos de asignación no responden sólo a principios de justicia determinados en momentos determinados, sino aspectos específicos de cada caso. En el caso de las vacunas en emergencias, parece haber muchos aspectos específicos que no son tomados en cuenta o que son dejados de lado al usar mecanismos como la lotería justa. Por ejemplo, pensemos en todas las razones que no se agotaron antes por atender al criterio de la falta de tiempo para deliberar. Pensemos en todos los criterios médicos ${ }^{9}$ que podrían funcionar como mejores razones para una deliberación que tuviera como resultado que un mecanismo de asignación discrecional.

Lo que trato de decir es que no es obvio que, en el caso de asignación de vacunas, se pueda decir sin más que la razón ha sido derrotada, quitándome el sombrero ante Elster, y que lo único que puede salvarnos de la indeterminación es

9 Criterios del tipo de los QALYs y la mejor recepción por especificidades de cada paciente. Algunos de los criterios médicos que se involucran en este tipo de decisiones pueden ser revisados en Waring (2004). 
la lotería justa. Podría ser que a la luz de las razones que dan los criterios médicos pudiera ser mejor una asignación como la que proponen los protocolos mundiales. Pero en este caso propondría un mecanismo discrecional real y con toda la pompa, no el tipo de loterías cargadas que no resuelven su identidad entre mecanismo discrecional o mecánico. Si lo que he argumentado y descrito es por fortuna correcto de alguna forma, entonces creo que podría resumir la conclusión de la siguiente manera: lo que propone Peterson es una lotería cargada; ésta no es una lotería bien realizada, una lotería bien realizada es una lotería justa, una lotería justa cumple con respetar ciertos principio de justicia y de imparcialidad, cosa que la lotería cargada no puede hacer, sin embargo, la lotería justa no es el mecanismo por asignación perfecto y puede pensarse en otros mejores. Todo esto pensando sólo en el caso de asignación de vacunas en caso de emergencias.

\section{Bibliografía}

Binmore, K. (2011). Teoría de juegos: una breve introducción. España: Alianza Editorial.

Broome, J. (1990). Ethics out of Economics. Reino Unido: Cambridge University Press.

Elster, J. (2000). La ética de las decisiones médicas. En Elster, J. y Herpin, N. (Comps.). La Ética de las Decisiones Médicas. España: Gedisa.

Elster, J. (1992). Local Justice: how institutions allocate scarce goods and necessary burdens. Estados Unidos de América: Cambridge University Press.

Elster, J. (1989). Solomonic Judgments: studies in the limitations of rationality. Francia: Maison des Sciences de l'Homme/ Cambridge University Press. 
Hirose, I. (2010). Should we select people randomly?. En Bioethics, 24(1), 45-46.

Organización Mundial de la Salud. (2016). WHO pandemic phase descriptions and main actions by phase. Disponible en http://www.who.int/influenza/resources/ documents/pandemic_phase_descriptions_and_actions.pdf?ua=1. Consultado el 19 de mayo 2016.

Peterson, M. (2008). The moral importance of selecting people randomly. En Bioethics. 22(6) 321-27.

Rawls, J. (2006). Teoría de la justicia. México: Fondo de Cultura Económica.

Stone, P. (2011). The Luck of the Draw: the role of lotteries in decision making. Estados Unidos de América: Oxford University Press.

Stone, P. (2007). Why lotteriess are just?. En The Journal of Political Philosophy, 15(3), 276-95.

Waring, D. (2004). Medical Benefit and the Human Lottery: an egalitarian approach to patient selection. Países Bajos: Springer. 


\section{Resumen}

En este texto se argumenta a favor de la idea de que una lotería justa es un mecanismo de asignación más justo en el caso de la asignación de vacunas en casos de emergencia. Al decir que es más justo, lo hago en contraposición a la propuesta de lotería cargada. La idea es que una lotería justa cumple con los criterios para ser invocada además de que es una forma de romper la indeterminación generada por la incapacidad de deliberar, para concluir en que sólo una lotería justa es una lotería en sentido estricto según la descripción de un mecanismo por aleatoriedad.

Palabras clave: lotería justa, lotería cargada, justicia, asignación.

\section{Abstract}

In this article I argue that a just lottery is a fairness assignation mechanism in the case of assignation of vaccines for emergency cases, in contrast to the proposal of a charged lottery. The idea is that a just lottery fulfil the criterion under which it is called, besides it is a way to avoid the indeterminacy that results from our incapacity to deliberate. In conclusion, only a just lottery is a lottery in strict sense, according to the description of a randomness mechanism.

Key words: just lottery, charged lottery, fairness, assignation. 
